\title{
Die either on the gallows, or of the pox
}

\section{The Great Pox: The French Disease in Renaissance Europe}

by John Arrizabalaga, John Henderson and Roger French

Yale University Press: 1997. Pp. 352. \$35, £25 William Bynum

When AIDS forced itself into the public's consciousness in the early 1980 s, historians were encouraged to find parallels between our modern scourge and the sudden appearance of syphilis in Europe half a millennium before. Ever willing to oblige, my colleagues and I pointed out a few similarities: the panic generated by a new disease, the search for scapegoats, the moralizing even the conclusion that both afflictions were the 'wages of sin'.

It is one of the many virtues of this admirable book to demonstrate how generic, if not actually specious, such parallels are. AIDS rates only one passing mention; nor is the authors' subject the spirochaetal disease that we know as syphilis. Rather, Arrizabalaga, Henderson and French seek to examine what the condition commonly called the 'French disease', or mal francese, meant to doctors, laymen and sufferers from the late fifteenth century. Their concern is with perceptions and responses rather than the prehistory of a modern disease. There are no new insights here on that hardy perennial: "Was syphilis a New World import brought back by Columbus' sailors, or an Old World disease newly transmuted and, perhaps, newly transmitted sexually?".

That this disease, which broke out in Naples, Florence, Ferrara and other Italian cities from 1496, did appear to many contemporaries to be new is not in doubt. And by calling it the French disease, they implicated the invading troops of King Charles VIII of France in its spread. The attempt of the French to call it the Neapolitan disease was less successful. The Columbus hypothesis was not part of the original debate, however; nor did everyone subscribe to the proposition that this was truly a new scourge. Nicolò Leoniceno (1428-1524) - the long-lived and tireless advocate of humanistic medical reform through a return to the solidity of Hippocrates, Galen and other Greek authors argued, with the author of Ecclesiastes, that there is no new thing under the sun. Hippocrates had seen it all and, under other names such as leprosy or elephantiasis, the French disease had ever plagued mankind.

Nor, throughout the sixteenth century, was the French disease ever exclusively venereal in its perceived mode of transmission. For one thing, priests, bishops, cardinals and popes suffered alongside the common people. 'Virtuous ladies' as well as prostitutes and soldiers fell victim to it. For another, the French disease did not begin, as does modern syphilis, with a genital chancre, but exhibited a mass of symptoms and signs. These included rash (the great pox, as distinguished from smallpox), intense pain in the bones and joints, sores, scabs and pustules. The genitals were implicated often enough to place unclean sexual intercourse among the contributing factors, however, and lues venerea became one of the disease's many names during the century.

The sexual dimension certainly reinforced the religious and moral overtones that the disease acquired early on, but in the religious context of Renaissance Europe, the existence of disease itself posed the very questions that had long ago plagued Job. The French disease was thought particularly loathsome, however (in Strasbourg, even the lepers shunned those suffering from it), and Jews, prostitutes and other marginal groups were sometimes singled out for castigation.

Nevertheless, from the extensive evidence of this volume, it is a mistake to isolate the French disease from more general medical concerns of the age. From the early series of public disputations on its nature and causes - the wonderfully named doctors Pistorius and Pollich who disputed in Germany could be characters from Cymbeline or another late-Shakespearean romance - to the continuing debates about the best form of treatment, professional medical issues loom large. Mercury and guaiac bark emerged as the principal drug alternatives. Guaiac's New World origin eventually gave credence to the Columbus hypothesis (God placed remedies near diseases), but, in the sixteenth century, physicians were more concerned with justifying their preference by appealing to the relationship between the properties of drugs and the nature of the disease.

Mercury was a traditional treatment for a variety of skin disorders, but it was disagreeable and could be dangerous. It was a mainstay of surgeons, Paracelsians and quacks; learned physicians, who recognized its potency, insisted that its real danger lay in incorrect administration by incompetent hands. By contrast, decoctions of guaiac wood were new and easier on the patient, but also more expensive and, according to many, less effective. Despite its cost (the Fugger family in Germany made a fortune

\section{IMAGE UNAVAILABLE FOR COPYRIGHT REASONS}

French made: a patient suffers from the pox in this woodcut from 1520 .

importing it), guaiac was commonly used in Italian hospitals for 'incurables'.

These hospitals, here analysed in detail, began to be founded in many Italian cities from the early sixteenth century as a response to the new disease. Records from the Spedale di San Giacomo in Rome belie the common historical caricature of early hospitals as 'gateways to death'; mortality rates there were in the range of 10 to 15 per cent. Admissions were predominantly male, although females had higher mortality rates, probably because they were likely to be more badly nourished and more desperately ill than their male counterparts. The clinical descriptions do not permit modern diagnoses, but many patients were perceived at the time as suffering from the French disease. When the holy wood' (as guaiac was known) was being administered, patients were especially keen to be admitted.

Arrizabalaga and his colleagues have elucidated these and many other aspects of their subject. They argue convincingly that the French disease catalysed both institutional and conceptual change within Renaissance medicine. They are chary of calling this change 'progress'. Rather, they insist that our forebears had knowledge that was just as meaningful to them as our own is to us. Or, as the radical medical reformer Paracelsus (1493-1541) once remarked: "What was true for the Greeks is not true for us. Truth must be born in its own land." And, he might have added, in its own time.

William Bynum is at the Wellcome Institute for the History of Medicine, 183 Euston Road, London NW1 2BE, UK. 